\title{
Influence of spray formulation surface tension on spray droplet adhesion and shatter on hairy leaves
}

\author{
J.J. Nairn, W.A. Forster and R.M. van Leeuwen \\ Plant Protection Chemistry ${ }_{N Z}$, P O Box 6282, Rotorua 3043, New Zealand \\ Corresponding author: alison.forster@ppcnz.co.nz
}

\begin{abstract}
An empirical spray droplet adhesion model, developed to predict the adhesion of spray formulations to non-hairy leaf surfaces based on their specific wettability, has previously been improved to allow predictions to hairy leaves, since it had been discovered that leaf hairs cause a significant, consistent increase in droplet shatter compared to nonhairy leaves (super-hairy leaves demonstrate distinctly different adhesion behaviour). The current study investigated the effect of spray formulation surface tension on droplet adhesion to hairy leaf surfaces. The amount of shatter on hairy leaves was found to increase with decreasing surface tension. The relationship derived improved the adhesion model. This enables the model to better predict the effect of spray formulation on spray droplet adhesion of hairy leaf species.
\end{abstract}

Keywords contact angles, spray, wettability, adhesion, leaf hairs, modelling.

\section{INTRODUCTION}

To maximise total spray retention to foliage, droplets that impact with a leaf must remain on the plant. When a droplet impacts a leaf there are three possible outcomes, namely adhesion (the drop "sticks" on initial impact), bounce and shatter. These rebounding (bouncing) or shattered droplets can then continue their journey through the canopy depositing at lower levels in the canopy or on the ground (Schou et al. 2012). In order to be able to model spray retention to plants, the two primary mechanisms involved, adhesion (or bounce) and shatter must be modelled, requiring a good understanding of the processes involved. Good progress has been made, firstly in the development of empirical models for adhesion (Forster et al. 2005) and then the ultimate goal, process-driven (driven by physical processes and their associated physiological parameters) models for bounce/ adhesion and shatter to predict spray retention (Mercer et al. 2007; Forster et al. 2010; Schou et al. 2012; Dorr et al. 2013), but the effect of hairy leaves on spray retention has until recently been ignored.

The empirical spray droplet adhesion model developed by Forster et al. (2005) predicts adhesion of droplets (ca 100 to $1000 \mu \mathrm{m}$ diameter) of any aqueous formulation (pure water through to emulsifiable concentrate; with dynamic surface tensions of 20 to $72 \mathrm{mN} / \mathrm{m}$ ), impacting leaves at velocities up to terminal, and leaf angles up to $67.5^{\circ}$. This model uses contact angle measurements as a rapid and easy way to quantify the relative wettability of a target plant surface (Gaskin et al. 2005). However, the model was confounded by hairy (pubescent) leaves (Figure 
1). Nairn et al. (2013) identified that hairy species exhibited two different adhesion behaviours, either penetrating hairs to contact the leaf surface (hairy leaves) or held fully supported on the hair mat (super-hairy leaves). Generally visually obvious by the thick hair coverage, super-hairy can be differentiated from simply hairy leaves during the contact angle measurements. Unifying these two leaf types into the adhesion model required different approaches. For super-hairy leaf surfaces (relatively uncommon amongst weed and crop species in New Zealand compared to hairy and non-hairy), this was done by introducing a cushioning factor found to be roughly proportional to the measured height of the hair mats (Nairn et al. 2013). The majority of 'hairy' plant species studied were of the hairy-leaf category (i.e. not super-hairy). These were observed to have very low adhesion due to a significant increase in droplet shatter. The leaf hairs impinge on the droplet, disrupting its integrity and promoting shatter upon impact with the leaf surface. It was found that a simple global hairy leaf correction factor $(-46 \%)$ could be employed to account for this, i.e. $46 \%$ more shatter is predicted on hairy leaves than on non-hairy.

The adhesion models can be used to forecast which formulations (primarily surface tension) would likely give better spray retention on which plant species. The hairy leaf shatter constant $(-46 \%)$ was established by considering only the average species adhesion for all of the formulations studied, spanning a wide range of surface tensions. However, this average ignores any changes in shatter with formulation surface tension. The objectives of the current study were to investigate (1) whether surface tension influences the extent to which droplets shatter on hairy leaves, and if so, (2) whether the model could be further improved to better predict the effect of spray formulation on spray droplet adhesion by hairy leaf species.

\section{MATERIALS AND METHODS}

All plant leaf surfaces studied were of the hairy category, i.e. not super-hairy (a different adhesion mechanism) or non-hairy (satisfactorily modelled). Lycopersicon esculentum Mill. (tomato), Myosotis arvensis L. (forget-menot), Lamium purpureum L. (red dead-nettle),

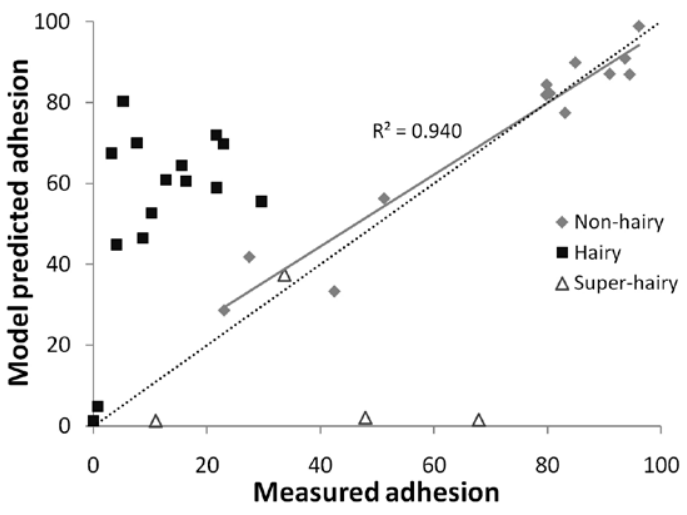

Figure 1 Performance of the original (non-hairy) adhesion model (Forster et al. 2005). Note: only the non-hairy data have been fitted. Non-hairy and super-hairy data are the same as Nairn et al. (2013). Dotted line indicates the perfect 1:1 model fit.

and Conyza bonariensis L. Cronq. (Argentine fleabane), were grown from seed in $\mathrm{PPC}_{\mathrm{NZ}}$ / Bloom potting mix (Daltons, Matamata, New Zealand), raised under controlled environmental (CE) conditions with $70 \%$ relative humidity, $12 \mathrm{~h}$ photoperiod at ca $450 \mu \mathrm{mol} / \mathrm{m}^{2} / \mathrm{s}, 23^{\circ} \mathrm{C} / 15^{\circ} \mathrm{C}$ day/ night temperatures and used at 3-5 weeks of age. Digitalis purpurea L. (foxglove) and Onopordum acanthium L. (Scotch thistle) were harvested from naturally seeded populations. Actidinia deliciosa var. deliciosa cv. Bruno (kiwifruit) was grown from cuttings, raised in a shade house with regular watering and used at about 1 year of age. For all experiments the adaxial surfaces of new, fully-expanded leaves were studied.

Distilled deionised water was studied alone, or mixed with one of three commercial surfactants: Silwet ${ }^{\circledR} \quad$ L-77 ${ }^{\mathrm{TM}}$ (Momentive Performance Materials, Tarrytown, NY, USA; a trisiloxane ethoxylate mean EO 7.5), Ecoteric T20 (Huntsman, Victoria, Australia; Polyoxyethylene (20) sorbitan monolaurate) and Teric G12A6N (Huntsman, Victoria, Australia; an alcohol ethoxylate), All three surfactants were used at a rate of $0.1 \% \mathrm{w} / \mathrm{v}$, with Silwet ${ }^{\circledR} \mathrm{L}-77^{\mathrm{TM}}$ also being tested at $0.01 \%$, to generate a range of surface tensions. The fluorescent agent Blankophor $\mathrm{P}$ 167\% (Bayer AG, Leverkusen, Germany) was incorporated into all treatments $(1 \% \mathrm{w} / \mathrm{v})$ to allow UV visualisation of the droplets. Analytical 
grade acetone was used for the contact angle and mean adhesion measurements as described in full elsewhere (Nairn et al. 2013).

The pertinent points for this study are as follows. Droplets $(2 \mu \mathrm{l})$ of an acetone+water solution (50\% v/v acetone) were applied to the youngest, fully expanded surfaces of freshly detached leaves, and the contact angles $(n=21)$ measured using an Optical Contact Angle Meter (CAM 200, KSV Instruments). For the adhesion experiments, ten drops were impacted onto each of ten replicate leaves, taken from different plants, and repeated for each formulation, droplet fall distance, leaf angle and leaf surface studied. Droplets of each formulation were dropped from two heights $(35 \mathrm{~cm}$ and $92 \mathrm{~cm}$ ) giving a range of impact velocities (between 2.12 to 2.22 and 2.84 to $3.05 \mathrm{~m} / \mathrm{s}$, respectively), depending on the droplet size generated by an impulse-jet droplet generator (mean $861 \pm 74 \mu \mathrm{m}$ in diameter). Droplet shatter occurs with high energy impacts where the droplet cannot retain its coherence, and is related to droplet formulation characteristics, droplet diameter and velocity (Forster et al. 2010; Mercer et al. 2010). While the size of the droplets used in the current study is on the high end of the spray droplet spectrum, and much larger than the VMD produced by commonly used spray nozzles, their impact velocity is lower than terminal velocity (ca 3.47 $\mathrm{m} / \mathrm{s}$ ), meaning that we can scale the results for smaller droplets, impacting the target surface at much higher impact velocities, as would be the case in reality for ground sprayers. The droplets fell onto detached leaves held on a solid surface at three angles $\left(0,22.5\right.$ and $\left.45^{\circ}\right)$. If a droplet stuck on initial impact, this was defined as adhesion; if it bounced or shattered, regardless of distance, this was defined as no adhesion.

\section{RESULTS AND DISCUSSION}

The results of mean adhesion for droplets of different formulations, impacting the different hairy-leaf surfaces from two different heights and three different leaf angles, are given in Table 1 . These species should be moderate- or easy-towet (Gaskin et al. 2005), yet all demonstrate low adhesion observed to be due to shatter caused by leaf hairs. Much higher adhesion would be expected had the leaf surfaces been non-hairy. Species used in an earlier experiment and repeated in this study were grown at different times of the year and growing conditions. Different growing conditions can alter the leaf wettability (Forster \& Van Leeuwen 2010) as demonstrated by the measured contact angle (Table 1). Overall, for a fall distance of $35 \mathrm{~cm}$, mean adhesion increased with decreasing surface tension as expected (Forster et al. 2005). At a fall distance of $92 \mathrm{~cm}$, formulation and species had little effect on adhesion, which remained low, ranging from $0 \%$ to $18.7 \%$ (Table 1 ).

A shatter value, replacing the $-46 \%$ constant used in the previous adhesion model (Nairn et al. 2013), was established for each probe solution by iterative optimisation (Figure 2). This optimisation adjusted this shatter value to minimise the difference between the actual measured adhesion and the model predicted adhesion across all but two of the species studied. These two excluded species, Argentine fleabane and Scotch thistle, had very low measured adhesion which when included skewed the model, improving the overall fit but worsening the fit for the majority of the species. Nevertheless, the shatter values established still improved the fit for both these species (Figure 3). Their very low adhesion was attributed to an extremely rugous leaf surface, which may contribute to droplet

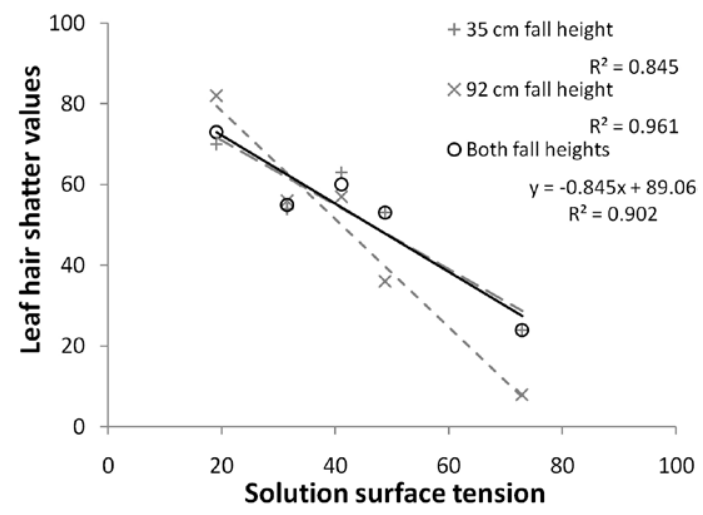

Figure 2 Surface tension specific shatter values for hairy leaves established by iterative optimisation. Three shatter regimes were optimised using (1) only the $35 \mathrm{~cm}$ fall data, (2) only the $92 \mathrm{~cm}$ fall data and (3) all the fall height data combined. 
Table 1 Mean contact angle ( ${ }^{\circ}$; CA) for species and measured mean percent adhesion for drops $(861 \pm 74$ $\mu \mathrm{m}$ diameter) of different formulations (with different surface tensions; $\mathrm{mN} / \mathrm{m})$ falling $35 \mathrm{~cm}(2.12$ $2.22 \mathrm{~m} / \mathrm{s})$ and $92 \mathrm{~cm}(2.84-3.05 \mathrm{~m} / \mathrm{s})$.

\begin{tabular}{|c|c|c|c|c|c|c|c|c|c|c|c|}
\hline \multirow[b]{2}{*}{ Species } & \multirow[b]{2}{*}{$\mathrm{CA}$} & \multicolumn{2}{|c|}{$\begin{array}{c}\text { Water } \\
72.9 \mathrm{mN} / \mathrm{m}\end{array}$} & \multicolumn{2}{|c|}{$\begin{array}{c}0.1 \% \text { Eco. } \\
48.8 \mathrm{mN} / \mathrm{m}\end{array}$} & \multicolumn{2}{|c|}{$\begin{array}{c}0.01 \% \mathrm{~L} 77 \\
41.1 \mathrm{mN} / \mathrm{m}\end{array}$} & \multicolumn{2}{|c|}{$\begin{array}{l}0.1 \% \text { Teric } \\
31.5 \mathrm{mN} / \mathrm{m}\end{array}$} & \multicolumn{2}{|c|}{$\begin{array}{c}0.1 \% \mathrm{~L} 77 \\
19.1 \mathrm{mN} / \mathrm{m}\end{array}$} \\
\hline & & 35 & 92 & 35 & 92 & 35 & 92 & 35 & 92 & 35 & 92 \\
\hline \multicolumn{12}{|c|}{ Mean adhesion data for the species cultivated for this experiment } \\
\hline Forget-me-not & 77.1 & 3.0 & 0.0 & 7.1 & 0.0 & 9.0 & 0.0 & 10.3 & 0.0 & 12.3 & 0.0 \\
\hline Tomato & 70.3 & 36.3 & 3.3 & 40.0 & 5.0 & 35.7 & 5.7 & 71.3 & 18.7 & 67.3 & 13.0 \\
\hline Foxglove & 66.9 & 44.7 & 9.3 & 18.7 & 4.7 & 37.0 & 7.7 & 42.7 & 5.3 & 44.7 & 2.7 \\
\hline Kiwifruit & 65.0 & 18.7 & 1.0 & 21.0 & 2.0 & 16.3 & 0.0 & 39.3 & 1.7 & 27.3 & 0.7 \\
\hline Argentine flea. & 63.9 & 5.3 & 0 & 3.3 & 0 & 6.7 & 0 & 6.0 & 0 & 4.7 & 0 \\
\hline Red dead nettle & 63.1 & 19.7 & 3.0 & 31.3 & 1.3 & 21.0 & 0.3 & 31.7 & 4.7 & 40.0 & 2.7 \\
\hline Scotch thistle & 49.2 & 7.7 & 0 & 9.3 & 0.3 & 5.0 & 0.3 & 10.0 & 0 & 10.0 & 0 \\
\hline
\end{tabular}

Mean adhesion data from Nairn et al. (2013) included in the shatter constant fitting process

\begin{tabular}{|c|c|c|c|c|c|c|c|}
\hline Forget-me-not & 75.4 & 12.0 & 3.7 & 11.3 & 0.0 & 20.7 & 5.0 \\
\hline Red dead nettle & 70.1 & 20.7 & 1.0 & 12.3 & 1.3 & 25.7 & 0.7 \\
\hline Argentine flea & 64.3 & 23.0 & 0.0 & 20.3 & 17.3 & 34.0 & 3.3 \\
\hline Tomato & 55.5 & 17.7 & 12.7 & 57.7 & 14.0 & 21.3 & 14.3 \\
\hline Velvet leaf & 55.3 & 4.7 & 0.0 & 34.3 & 0.0 & 7.3 & 0.0 \\
\hline Foxglove & 5.6 & 20.0 & 6.7 & 44.3 & 8.3 & 42.0 & 8.7 \\
\hline
\end{tabular}

LSD for all mean adhesion treatments $(\mathrm{P}<0.05)=6.6$

Mean measured adhesion (\% of droplets)

$$
\begin{array}{llllllllll}
17.9 & 3.1 & 18.7 & 1.9 & 23.9 & 4.2 & 30.2 & 4.3 & 27.5 & 3.9
\end{array}
$$

Mean predicted adhesion (\% of droplets)

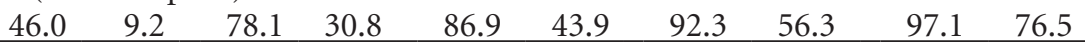

shatter beyond that attributed to the leaf hairs and, as both species were reasonably easy-towet, the droplets spreading/conforming to the rugous surface may have also contributed to false shatter recordings. Separate shatter values were established for each fall height data set in isolation as well as both data sets combined (Figure 2). Increasing impact velocity significantly increases shatter on non-hairy leaves (Dorr et al. 2013). It is possible that the effect of surface tension on hairy leaf shatter could also be amplified by the greater impact velocity at the higher fall height. Even discounting the reduction in adhesion due to leaf hair shatter, the adhesion models (Forster et al. 2005) predict a $16 \%$ decrease in adhesion at the higher fall height, due to increased bounce and shatter. This combined effect severely truncates the data set as most of the species studied have adhesion close to zero. There was no obvious shift in the surface tension-shatter relationship between the fall height data sets to make a compelling case for the fall heights to be treated separately (Figure 2). Figure 2 demonstrates that the surface tension of the solution influences the extent to which droplets shatter on hairy leaves; high surface tension formulations such as water $(72.9 \mathrm{mN} / \mathrm{m})$ show a moderate (ca 25\%) reduction in adhesion, whereas, the low surface tension formulations such as $0.1 \%$ Silwet L-77 $(19.1 \mathrm{mN} / \mathrm{m})$ show a significant (ca $75 \%$ ) reduction in adhesion due to an observed increase in shatter.

There was a strong inverse correlation $\left(\mathrm{R}^{2}=0.90\right.$, Figure 2) between the shatter value optimised for surface tension and the surface tension of the formulation (i.e. more shatter occurred due to leaf hairs at lower surface tensions). This linear regression allows the surface tension-shatter relationship to be derived and incorporated into the adhesion model (Eqn 1, in bold). By using this relationship the shatter 'constant' is no longer fixed but adjusts the predicted adhesion due to 
shatter caused by hairy leaves, for any formulation surface tension desired.

$$
\begin{aligned}
& \text { Adhesion (\% of droplets impacting })=\frac{100 e^{F}}{\left(1+e^{F}\right)}-(-\mathbf{0 . 8 4 5 1} \gamma+\mathbf{8 9 . 0 6 5}) H \\
& \qquad F=13.52-\frac{3.34 V}{1+C}-0.003295 \theta^{1.64}+0.0770\left(\gamma_{w}-\gamma_{t}\right)-0.0894 \varphi
\end{aligned}
$$

Where $V=$ droplet velocity at leaf impact, $\theta=$ leaf angle relative to droplet direction, $Y_{w}=$ surface tension of water, $Y_{t}=$ dynamic surface tension of the falling droplet at the time of impact, $\Delta=$ average static contact angle for $50 \%$ aqueous acetone droplets on the leaf surface, $C=$ superhairy type adhesion cushioning factor $(C=0$, for this study, as leaves were not super-hairy), $H=$ hairy leaf designator $(1=$ hairy and $0=$ non hairy or superhairy), and $\gamma=$ the equilibrium surface tension of the formulation. Note: only that in bold was adjusted in this study.

The new model (Eqn 1) incorporating the hairy leaf shatter-surface tension relationship increasingly improved the model prediction for adhesion to hairy leaves as the formulation surface tension decreased compared to the earlier

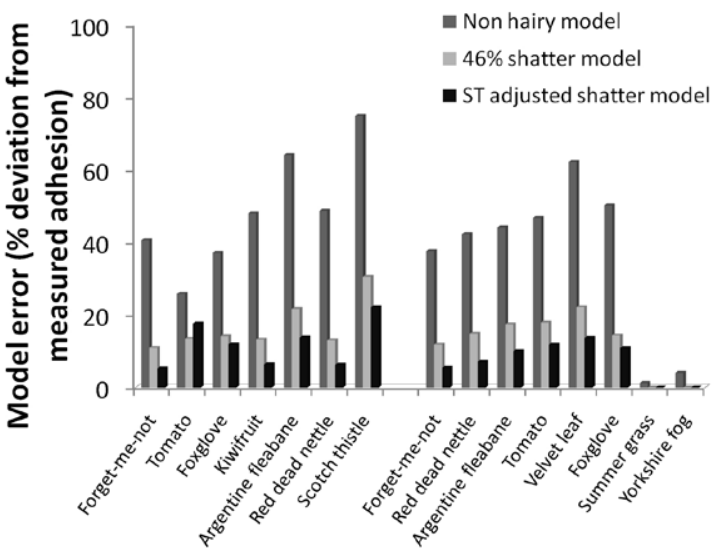

Figure 3 Performance of each adhesion model: non-hairy (Forster et al. 2005), -46\% shatter constant (Nairn et al. 2013), and the new model, adjusted for the effect of formulation surface tension (ST) on shatter by hairy leaves, for each hairy leaf species. This graph presents the data averaged over all categories, droplet fall height, leaf angle and formulation, on each leaf surface. The species listed first were those cultivated for the current experiment, the subsequent species, listed after the break, were those used in the Nairn et al. (2013) experiment. models (Figure 4). While the average hairy leaf shatter constant, $-46 H$ (Nairn et al. 2013), was serviceable, giving reasonable estimates for hairy leaf species, it suffered from the same systematic drift with surface tension as the original model (Figure 4). The new model accounts for this, predicting a decrease in adhesion due to increasing shatter by leaf hairs with lower surface tensions. The performance of the new model (Eqn 1) across all species was excellent and in general improved on the basic $-46 \%$ model (Figure 3). The new model can be used to predict total adhesion for hairy, non-hairy and superhairy species $\left(\mathrm{R}^{2}=0.95\right.$, Figure 5$)$.

Adhesion is the first stage in spray droplet retention. Total spray retention depends on a number of mechanisms, recapture, run off, etc. Should $100 \%$ adhesion be achieved these secondary mechanisms become irrelevant. Leaf hairs (in the hairy-leaf regime) promote shatter therefore recapture could be a major contributor

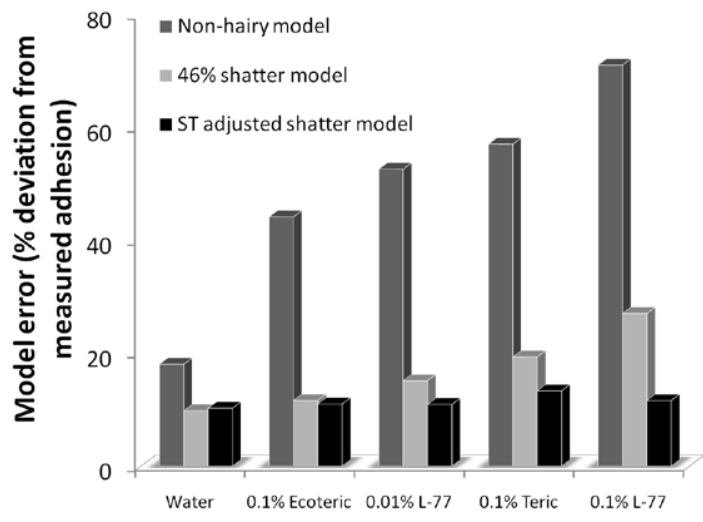

Figure 4 Performance of each adhesion model: non hairy (Forster et al. 2005), $-46 \%$ shatter constant (Nairn et al. 2013), and the new model (Eqn 1), for each formulation. This graph presents the data averaged over all categories, droplet fall height, leaf angle and leaf surface, for each formulation. 


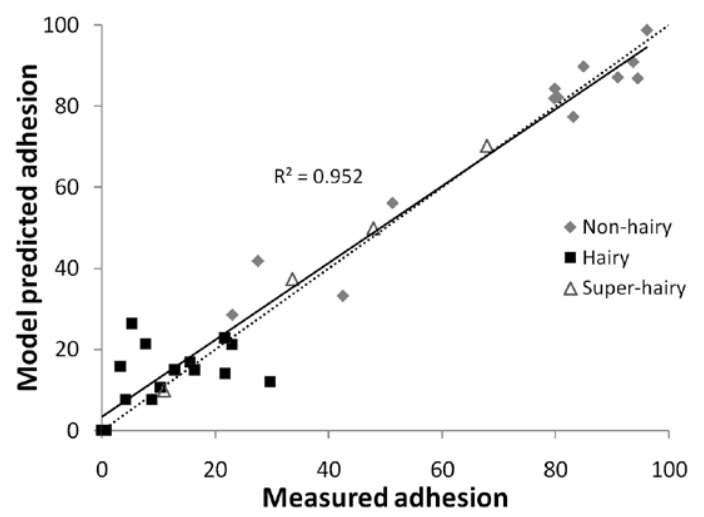

Figure 5 Performance of the new model (Eqn 1) predicted adhesion versus actual measured adhesion (all the species have been fitted). Nonhairy and super-hairy data are the same as Nairn et al. (2013). Dotted line indicates the perfect 1:1 model fit.

to retention, but this depends on plant canopy architecture (a sparse or single layer canopy has a limited ability to recapture). Pinning, whereby a portion of the droplet remains adhered 'pinned' to the surface after shatter, also could be significant (Boukhalfa et al. 2014). The shattersurface tension relationship established here would be quite relevant to modelling the pinning retention on hairy leaves.

In conclusion, this study furthers the understanding of spray droplet adhesion and shatter on hairy leaf surfaces. The new model is an improvement and should allow more effective prediction of adhesion to hairy leaves, which in turn can be used to forecast which formulations should give better final retention on hairy leaf species.

\section{ACKNOWLEDGEMENTS}

This research was funded by the New Zealand Ministry of Business, Innovation and Employment (MBIE; Contract No. C10X0811: Undermining Weeds).

\section{REFERENCES}

Boukhalfa $\mathrm{HH}$, Massinon M, Belhamra M, Lebeau F 2014. Contribution of spray droplet pinning fragmentation to canopy retention. Crop Protection 56: 91-97.
Dorr GJ, Kempthorne DM, Mayo LC, Forster WA, Zabkiewicz JA, McCue SW, Belward JA, Turner IW, Hanan J 2013. Towards a model of spraycanopy interactions: Interception, shatter, bounce and retention of droplets on horizontal leaves. Ecological Modelling (in press).

Forster A, Van Leeuwen RM 2010. Characterisation of forest weed species and herbicide formulations to predict droplet adhesion and optimise spray retention Proceedings of the 17th Australasian Weeds Conference: 348-351.

Forster W, Mercer G, Schou W 2010. Processdriven models for spray droplet shatter, adhesion or bounce. Proceedings of the 9th International Symposium on Adjuvants for Agrochemicals: 277-285

Forster WA, Kimberley MO, Zabkiewicz JA 2005. A universal spray droplet adhesion model. Transactions of the ASAE 48: 1321-1330.

Gaskin RE, Steele KD, Forster WA 2005. Characterising plant surfaces for spray adhesion and retention. New Zealand Plant Protection 58: 179-183.

Mercer G, Sweatman W, Elvin A, Caunce J, Fulford G, Harper S, Pennifold R 2007. Process driven models for spray retention by plants. In: Wake $\mathrm{G}$ ed. Proceedings of the 2006 Mathematics-In-Industry Study Group. Pp. 57-85.

Mercer GN, Sweatman WL, Forster WA 2010. A model for spray droplet adhesion, bounce or shatter at a crop leaf surface. In: Fitt AD, Norbury J, Ockendon H, Wilson E ed. Progress in Industrial Mathematics at ECMI 2008. Mathematics in Industry 15. Springer-Verlag, Berlin. Pp. 937-943 (DOI: 10.1007/978-3-642-12110-4_151).

Nairn J, Forster A, van Leeuwen R 2013. "Universal" spray droplet adhesion model accounting for hairy leaves. Weed Research 53: 407-417.

Schou WC, Forster WA, Mercer G, Teske M, Thistle H 2012. Building canopy retention into AGDISP: Preliminary models and results. Transactions of the ASABE 55: 2059-2066. 